\title{
Coping with Imprecision in Strategic Planning: A Case Study Using Fuzzy SWOT Analysis
}

\author{
Hasan Hosseini-Nasab ${ }^{1,2}$, Amin Hosseini-Nasab ${ }^{3}$, Abbas S. Milani ${ }^{2 *}$ \\ ${ }^{1}$ Department of Industrial Engineering, Yazd University, Tehran, Iran; ${ }^{2}$ School of Engineering, University of British Columbia, Ke- \\ lowna, Canada; ${ }^{3}$ Department of Industrial Engineering, Amirkabir University of Technology, Tehran, Iran \\ Email: abbas.milani@ubc.ca
}

Received December $9^{\text {th }}, 2010$; revised December $27^{\text {th }}, 2010$; accepted December $30^{\text {th }}, 2010$.

\begin{abstract}
In this article, it is shown that using the conventional SWOT analysis in the vicinity of strategic regions in the matrix of internal and external factors, ambiguity can exist in defining final strategies. To cope with this difficulty and to enhance the accuracy of the underplaying decision process, a straightforward fuzzy SWOT analysis is presented and exemplified by extracting and analyzing strengths, weaknesses, opportunities and threats in a company known as KPPP. The analysis is performed based on actual field data using 90 external and 85 internal factors and a group of 12 experts. Next to the identification of the fuzzy SWOT matrix, it is shown that the external threats and internal weaknesses of KPPP can have stronger effects compared to its external opportunities and internal strengths.
\end{abstract}

Keywords: Fuzzy Applications, Internal and External Factors, Strategic Planning, SWOT Analysis

\section{Introduction}

It is well known that a company's success in today's competitive business environment requires its ability to create and update strategic plans [1-6]. While various management analysis techniques such as the Total Quality Management (TQM) [7-10] and Re-engineering [2,4] have proven to be beneficial for meeting organizational specific objectives, strategic planning remains the single most important element for companies' overall success. Reported case studies indicate that organizations using the principles of strategic planning are by far in better condition in marketing, profitably and beneficiation $[2,4,11,12]$.

Earlier studies have been performed on improving the classical strategic planning methods such as the strengths, weaknesses, opportunities, and threats (SWOT) analysis. Ghazinoory et al. [13] applied a fuzzy set approach to both the internal and external factors using conventional membership functions. The algorithm prioritizes and extracted the most significant strategies based on intensity of effects. Kuo-liang and Lin Shu-chen [14] proposed a fuzzy SWOT method to evaluate the competitive environment of different transshipment locations as international distribution centers (IDC) in the Pacific-Asian region. Their work suggested that the fuzzy method identifies more competitive locations as compared to the conventional SWOT. Zhangjiajie [15] presented a new fuzzy decision-making tool for small and medium enterprises (SMEs) under a set of ambiguous strategic policies. The model can assist SMEs to train their own core strengths and gradually explore their ideal strategies. Lee et al. [16] presented a mechanism for integrating a fuzzy cognitive map (FCM) within strategic planning simulations, where FCM helps decision makers understand complex dynamics between a certain strategic goal and related environmental factors. Wang and Chang [17] investigated the properties of fuzzy scenario analysis to cope with the issue of data shortage and the linguistic expression of experts. Their study successfully incorporated the fuzzy set theory into the scenario analysis such that uncertainties are accounted for. Kahraman1 et al. [18] proposed a method to evaluate different alternative strategies for an e-government application in Turkey. They used the SWOT approach in conjunction with the analytic hierarchy process (AHP) to prioritize their strategies. Shuliang et al. [19] proposed a hybrid approach for integrating a group Delphi, fuzzy sets and expert systems in developing marketing strategies. The method was specifically employed to help groups of managers undertake SWOT analysis. It is worth adding that next to the strategic planning area, fuzzy sets have been widely used in a range of applications including 
linear and nonlinear control, pattern recognition, financial systems, etc $[13,18,20]$.

This article is intended to first indentify a potential imprecision problem in the use of conventional SWOT analysis for particular strategic planning problems, and then present an application of a fuzzy SWOT method to resolve the problem. The method has been exemplified via a case study on the strategic planning of the KPPP company. The case is based on actual field data, collected from 12 experts based on 90 external and 85 internal decision factors. Section 2 reviews the basics of the conventional SWOT analysis. Section 3 identifies the potential problem with the conventional SWOT matrix and extends the analysis to the fuzzy method. Section 4 presents the KPPP's case study and discusses the results using a quantitative measure for determining the total distance between the obtained fuzzy internal and external factors. Section 5 concludes the article.

\section{Basic SWOT Analysis}

Strategic planning in an organization can involve making decisions on allocating resources such as capital and people. During strategic planning, main objectives are often presented as vision and mission statements and subsequently the company's strengths, weaknesses, opportunities, and threats (SWOT) are assessed [21-31]. The vision statement is an image or state to which the company aspires. It emphasizes the desire of where the company would be at a specific time. The nature of a business is often expressed in terms of its mission indicating the purpose of the business; for example, to design, develop, manufacture and market specific product lines for sales based on certain features to meet the identified needs of specific customer groups via certain distribution channels in particular geographic areas. Having built up a picture of the company's past and current achievements, the SWOT analysis can commence. The following four steps are considered for analyzing the internal factors:

1) All internal factors are scored based on their existing status in the company. The scores are crisp values and usually range from -2 to 2 as shown in Figure 1.

2) An overall importance coefficient/weight of 1 to 100 is assigned to each internal factor based on the viewpoints of experts. The weights are then normalized such that their sum is one.

3) The weighted score of each factor is calculated by multiplying the corresponding normalized importance

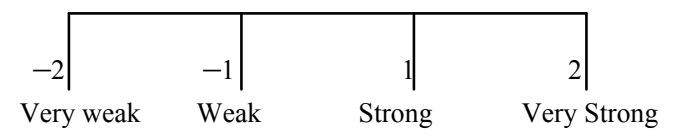

Figure 1. Scoring of the internal (or external) factors based on their importance. coefficient by the score of the factor from Step 1 .

4) The summation of the weighted scores is considered as the overall score of internal factors.

The external opportunities and threats to the company can fall in the areas such as customers, distribution channels, identities, substitute products, etc. The same procedure used for scoring the internal factors can be employed to evaluate the external factors; i.e., eventually an overall weighted score for the external factors is estimated.

Next, the company's overall internal and external scores are used to locate its position in a SWOT matrix as shown in Figure 2. The two overall internal and external scores define the coordinates of a strategic point that fall in one of the matrix cells. The matrix cells normally indicate known strategies for the managers. For example, if a company's position is located in cell \#1, growth strategies for adding new products are proposed; for cell $\# 9$, divestiture strategies are considered and so on.

\section{A Fuzzy SWOT Analysis}

Whilst a list of strategies should be suggested based on the final position of a company in the SWOT matrix, the crisp division of two adjacent cells may be a methodological limitation. This can be especially problematic when most of the data collected during the scoring process are qualitative. For instance, assuming a company with a total external score of 1.5 and a total internal factor of 1.001, the company's position is then placed in cell \#1 in Figure 2 and therefore, growth strategies for adding new products would be proposed. In a very similar case, assuming the same external score of 1.5 but with an internal score of 0.999 , the company's position would be placed in cell \#2 and consequently, a different strategy such as keeping existing situation would be proposed.

Hence, in such cases, two close internal or external scores can cause a major difference in the dictated

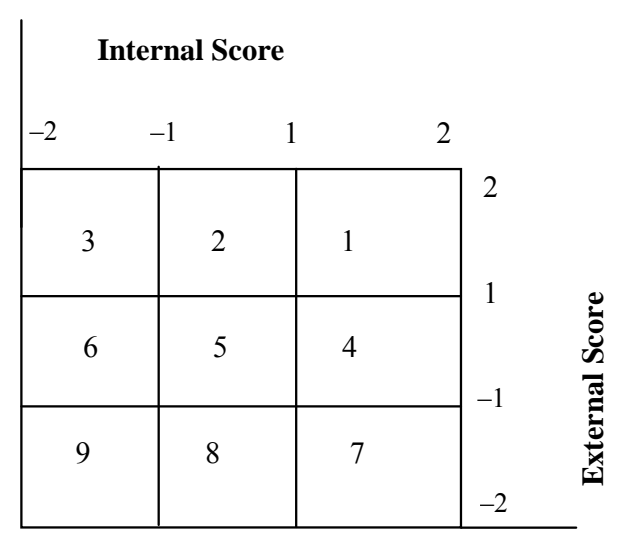

Figure 2. Matrix of internal and external scores. 
strategies, while practically there are no large differences between the companies' ability and status with respect to the internal and external factor values (in the presence example, 0.999 vs. 1.001).

To overcome the above difficulty, a fuzzy scale (Figure 3) for scoring the internal and external factors may be considered and consequently, the evaluation matrix can compass fuzzy regions as shown in Figure 4. Using this fuzzy approach, the likelihood of a company's strategic point falling in a weak/medium or medium/strong state in the vicinity of two adjacent cells varies gradually (with a reasonable slope of the membership function). As a result, a sudden change from the weak to medium or from the medium to strong state is avoided. For example, recalling Figure 4, internal scores of 0.999 or 1.001 would both be considered within the intersection of the weak and medium states.

The following steps are proposed within the fuzzy SWOT framework:

1) Analyze the background data and define company's vision.

2) List the company's all external environment factors, including political, economical, social and technological factors. For each factor, its sub-factors/attributes can also be defined.

3) List the company's all internal environment factors, including those related to the marketing, functional sources, employee, general management, information and quality management. For each internal factor, its attributes can also be defined.

4) List the effective internal and external factors based

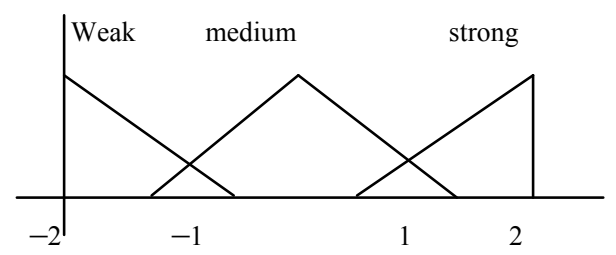

Figure 3. Triangular fuzzy numbers for scoring internal and external factors of the company.

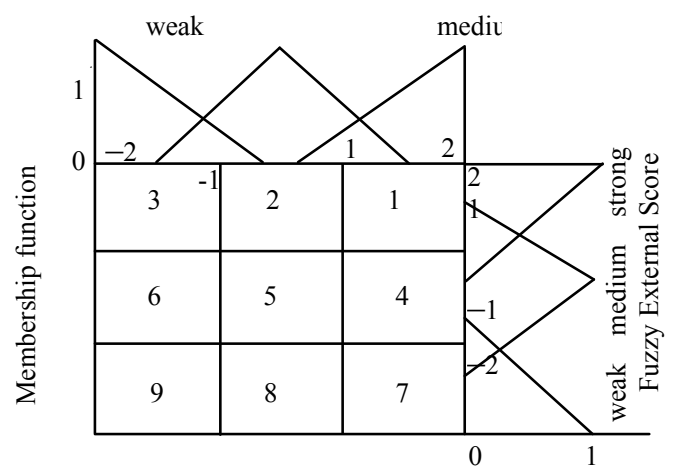

Figure 4. Fuzzy matrix of the internal and external factors. on the company's main objectives and activities.

5) Considering a factor (e.g., the $j$-th factor), define a triangular fuzzy number $\left(A_{j k}, B_{j k}, C_{j k}\right)$ for each of its attribute values (e.g., the $k$-th attribute) based on a scale of -2 to +2 , where -2 : complete threat/weakness, -1 : weak threat/weakness, +1 : weak opportunity/strength, + 2: complete opportunity/strength. $B_{j k}$ is the most probable (average) value, $A_{j k}$ is the minimum and $C_{j k}$ is the maximum (note that $A_{j k} \leq B_{j k} \leq C_{j k}$ ). If $N$ experts $(i=1, \cdots, N)$ are employed during data collection, each expert may define a fuzzy number such as $\left(A_{j k}^{i}, B_{j k}^{i}, C_{j k}^{i}\right)$. Averaging these fuzzy numbers for the $j$-th factor, $k$-th attribute gives [32]

$\left(A_{j k}, B_{j k}, C_{j k}\right)=\frac{1}{N}\left(\sum_{i=1}^{N} A_{j k}^{i}, \sum_{i=1}^{N} B_{j k}^{i}, \sum_{i=1}^{N} C_{j k}^{i}\right)$. The process can be repeated for all attributes of external and internal factors.

6) Define a weight, $w_{j k}$, for each attribute based on its influence on the company's activities and objectives by using a scale of 1 to 100 (subsequently the weights can be normalized to one). Weights may be found by brain storming among experts or by averaging individual weights from the experts.

7) Calculate an average fuzzy numbers $C_{j}$ for each factor based on its attribute values and weights:

$$
A_{j}=\sum_{k=1}^{n_{j}} w_{j k} A_{j k}, B_{j}=\sum_{k=1}^{n_{j}} w_{j k} B_{j k}, C_{j}=\sum_{k=1}^{n_{j}} w_{j k} C_{j k} ;
$$

where $n_{j}$ is the number of attributes for the $j$-th factor.

8) Calculate a total score of the internal factors (FIF) and a total score of the external factors (FEF) by summing the corresponding fuzzy scores $\left(A_{j}, B_{j}, C_{j}\right)$ from the previous step. Note that FIF and FEF will also be fuzzy numbers.

9) Locate the company's position in a fuzzy SWOT matrix based on the FIF and FEF values. The located coordinates should indicate a fuzzy triangular region, instead of a single point that would normally be obtained using the conventional SWOT.

\section{Case Study}

Due to the confidentiality reasons, let us name the company under study 'KPPP'. KPPP carried out various national and international activities. The IT department of KPPP has the role of facilitating the technology integration and IT service development towards integrated solutions. This department manages KPPP's electronic services and internal information systems. In the beginning of 2011, KPPP made the decision that it should revisit its strategic planning for a better performance.

The company's vision during strategic planning is defined, e.g., based on a better control over its future, the 
need for better circulation, environmental alterations, opportunities and threats and also cultural modifications. Considering the opportunity for a strategic evaluation of the company's production and service, the vision and objective of KPPP were defined as follows. "The company is capable of continuing the production and service with a high level of quality and quantity and with a stable progress, and it can aim at becoming the source of better services for other related industries. "

To apply the fuzzy SWOT method of Section III, data for both internal and external environmental factors were collected from a committee of 12 experts in the area. In doing so, the company's general background and its condition relative to the nation's activities were accounted for; e.g., the company's share in job security and employment.
1) All potential internal and external factors on KPPP's activities and aims were listed.

2) The effective factors were short-listed, regardless of their form of influence (positive or negative effect). It was recognized that an exact analysis of internal environment is essential in confronting weaknesses by utilizing strengths. Internal factors were classified into marketing, money, employees, general management, etc. The main external factors were grouped into political, social, economical, technological, etc. In total, 5 external and 7 internal factors were used (to be discussed for Tables 3 \& 4).

3) The attributes of each factor in Step 2 were identified. For instance, for the 'Economical' factor (Table 1), attributes were chosen as: more predictable cash flow,

Table 1. Fuzzy external factors (sample data for the "Economical” factor).

\begin{tabular}{|c|c|c|c|c|c|c|}
\hline \multicolumn{3}{|c|}{ fuzzy number } & \multicolumn{2}{|c|}{ Priorities (weights) } & \multirow[b]{2}{*}{ Factor and its Attributes } & \\
\hline$A_{1}^{m}$ & $B_{1}^{m}$ & $C_{1}^{m}$ & $\begin{array}{c}\text { on scale of } \\
{[1-100]}\end{array}$ & $\begin{array}{c}\text { Normalized } \\
\text { value }\end{array}$ & & \\
\hline 1 & 1.2 & 1.5 & 65 & 0.030 & More predictable cash flow & \multirow{6}{*}{$\begin{array}{l}\text { T. } \\
\text { O } \\
\text { O } \\
0 \\
. \\
. \\
.\end{array}$} \\
\hline-1.6 & -1.3 & -1 & 80 & 0.035 & Breakability to natural disaster & \\
\hline 0.1 & 0.2 & 0.4 & 77 & 0.034 & Gaining financial knowledge & \\
\hline 0.2 & 0.5 & 1.1 & 80 & 0.035 & Minimum salary & \\
\hline-0.8 & -0.4 & -0.1 & 49 & 0.023 & Rate of bank interest & \\
\hline$\ldots$ & $\ldots$ & $\ldots .$. & $\ldots$. & $\ldots$. & ....(total of 28 attributes) & \\
\hline
\end{tabular}

Table 2. Fuzzy internal factors (sample data for the "Employee” factor).

\begin{tabular}{|c|c|c|c|c|c|c|}
\hline \multicolumn{3}{|c|}{ Factor conditions } & \multicolumn{2}{|c|}{ Priorities } & \multirow[b]{2}{*}{ Factor and its Attributes } & \\
\hline $\begin{array}{l}\text { Minimum } \\
\text { amount }\end{array}$ & $\begin{array}{l}\text { Most possible } \\
\text { amount }\end{array}$ & $\begin{array}{l}\text { Maximum } \\
\text { amount }\end{array}$ & $0-1$ & $1-100$ & & \\
\hline 0.2 & 0.3 & 0.6 & 0.067 & 81 & Happy employees & \multirow{7}{*}{$\begin{array}{l}T \\
3 \\
\frac{3}{0} \\
0 \\
8 \\
8\end{array}$} \\
\hline-1.5 & -1 & -0.5 & 0.053 & 70 & Employee union & \\
\hline-1 & -0.6 & -0.2 & 0.068 & 83 & Employee shortage & \\
\hline 1.1 & 1.2 & 1.5 & 0.066 & 80 & $\begin{array}{l}\text { Employee with high perform- } \\
\text { ance }\end{array}$ & \\
\hline 0 & 0.5 & 1 & 0.069 & 84 & $\begin{array}{c}\text { Low level of employee pay- } \\
\text { ment }\end{array}$ & \\
\hline 0 & 1 & 1.9 & 0.053 & 70 & Skilled employee & \\
\hline$\ldots$ & $\ldots$. & $\ldots$. & $\ldots$. & $\ldots$ & (total of 15 attributes) & \\
\hline
\end{tabular}

Table 3. Fuzzy external environmental factor analysis of KPPP.

\begin{tabular}{cccccc}
\hline \multicolumn{3}{c}{ Final Score (fuzzy average) } & & \\
Minimum amount & $\begin{array}{c}\text { Most possible } \\
\text { amount }\end{array}$ & Maximum amount & $\begin{array}{c}\text { Number of } \\
\text { factors }\end{array}$ & External Group Title & \# \\
\hline-0.0072 & 0.005 & 0.0213 & 24 & Political & 1 \\
-0.0133 & -0.0065 & 0.0075 & 28 & Economical & 2 \\
-0.045 & -0.027 & 0.0091 & 20 & Social & 3 \\
-0.062 & -0.025 & 0.002 & 12 & Technological & 4 \\
0.103 & -0.041 & 0.018 & 6 & Others & 5 \\
$-\mathbf{0 . 2 3}$ & $-\mathbf{0 . 1 1}$ & $\mathbf{0 . 0 3 4}$ & 90 & FEF & \\
\hline
\end{tabular}


Table 4. Fuzzy internal environmental factor analysis of KPPP.

\begin{tabular}{|c|c|c|c|c|c|}
\hline \multicolumn{3}{|c|}{ Final Score (fuzzy average) } & \multirow{2}{*}{$\begin{array}{l}\text { Number of } \\
\text { Attributes }\end{array}$} & \multirow[b]{2}{*}{ Factor Group Title } & \multirow[b]{2}{*}{ \# } \\
\hline $\begin{array}{c}\text { Minimum } \\
\text { amount }\end{array}$ & $\begin{array}{c}\text { Most possible } \\
\text { amount }\end{array}$ & $\begin{array}{c}\text { Maximum } \\
\text { amount }\end{array}$ & & & \\
\hline-0.0745 & -0.0451 & -0.011 & 8 & Marketing & 1 \\
\hline-0.0638 & -0.023 & -0.0214 & 5 & Money & 2 \\
\hline-0.0061 & 0.02 & 0.063 & 11 & Activities & 3 \\
\hline-0.044 & -0.0243 & -0.0183 & 15 & Employee & 4 \\
\hline-0.0167 & -0.0149 & -0.0008 & 21 & General management & 5 \\
\hline-0.0362 & -0.0173 & -0.0016 & 10 & Information & 6 \\
\hline-0.0251 & -0.0002 & -0.0043 & 15 & Quality management & 7 \\
\hline-0.27 & -0.11 & -0.018 & 85 & FIF & \\
\hline
\end{tabular}

breakability to natural disaster, gaining financial knowledge, minimum salary, and rate of bank interest.

4) Fuzzy numbers using the linguistic scale of Figure 3 were assigned by each expert and an average score was found for each attribute of a factor as $\left(A_{j k}, B_{j k}, C_{j k}\right)$. Sample results are included in Tables 1 and $\mathbf{2}$ for the external 'Economical' and internal 'Employee' factors, respectively. The weight of each attribute within each factor category (e.g., political) was also determined contingent to its influence on the KPPP activities. A scale of 1 to 100 was used and the final weights were normalized.

1) The attribute scores within each factor group were averaged and a total score for the factor was calculated as $\left(A_{j}, B_{j}, C_{j}\right) ; j=1, \cdots, 12$. Complete results are shown in Tables 3 and 4. For instance, the weighted average of attribute scores in Table 1 for the 'Economical' factor resulted in $(-0.0133,-0.0065,0.0075)$ as indicated in

Table 3.

To locate the strategic position of KPPP in a SWOT matrix, the FEF and FIF values were calculated by summing the fuzzy number in Tables 3 and 4, respectively. It was found that $F E F=(-0.23,-0.11,0.034)$ and $F I F=(-0.27,-0.11,0.018)$. Consequently, the locations of the best, most probable, and worst strategic points were shown in Figure 5.

\subsection{Determining a Distance between the Internal and External Factors - a Decision-Making Case:}

Managers often intend to know which factors (external or internal) are more influential in their strategic decision making. The distance between the two fuzzy numbers of FIF $\left(a_{1}, a_{2}, a_{3}\right)$ and $\operatorname{FEF}\left(b_{1}, b_{2}, b_{3}\right)$ can be calculated as:

$$
d(F I F, F E F)=\frac{\left(a_{1}+2 a_{2}+a_{3}\right)-\left(b_{1}+2 b_{2}+b_{3}\right)}{4}
$$

In the KPPP case this gives:

$$
\begin{aligned}
& d(F I F, F E F)= \\
& \frac{[-0.27+2(-0.11)+0.018]-[-0.23+2(-0.11)+0.034]}{4}=-0.014
\end{aligned}
$$

Considering a negative distance $(F I F-F E F<0)$, it could be recommended that the total effect of the internal (strengths/ weaknesses) factors is greater than the total effect of the external (opportunities/threats) factors and therefore, more focus should be made on reducing the company's weaknesses and strengthening its strengths.

Finally, of the three strategic points in the Fuzzy SWOT matrix in Figure 5, two points have been located in the threatening area; i.e., emphasizing sizable external threats and internal weaknesses of KPPP. Therefore, close attention should be paid to the external threats and internal weaknesses in making strategies for this company. The only point located in the desirable area with positive factor values is point 1 (with the least possible external threats and internal weaknesses). Nevertheless, considering the minimum likelihood of this point, no strategy would be taken up on point 1 . In fact, only a small area portion $(<25 \%)$ of the overall triangle has fallen in the positive region. Both points 2 and 3 belong to a strategic cell with a score between 0 and -1 (medium-to-week).

\section{Conclusions}

Internal strengths and weaknesses are vital for strategic planning of companies to cope with the external threats and benefit from the external opportunities. One of the potential shortcomings of the conventional SWOT matrix was shown and a simple fuzzy SWOT approach was suggested to overcome the problem. The method was exemplified using a case study in the KPPP company. It was shown that the current strategic position of the KPPP company is identifiable as a three-point region by means 


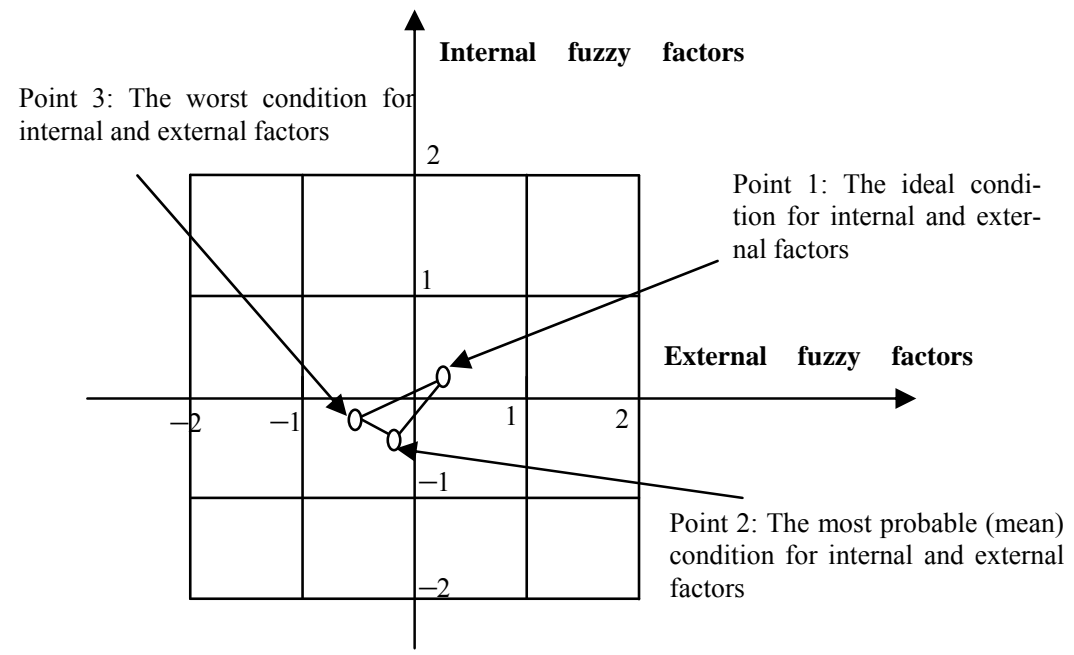

Figure 5. Strategic position of KPPP in the fuzzy SWOT matrix.

of the coordinates of FIF and FEF fuzzy numbers. In particular, the position of the ideal point with the least possible external threats and the least possible internal weaknesses, or the most external opportunities and the most internal strengths was revealed. Similarly, strategic points corresponding to the most probable (mean) and the worst condition were located. Eventually, based on the general position of the strategic triangle (relative position of the three points), a realistic strategy can be chosen. In the conventional SWOT analysis, only one point is identifiable and it may cause a decision ambiguity, specially in the vicinity of adjacent cells in the SOWT matrix. Further research is worthwhile to extend the fuzzy approach to more complex strategic planning models (e.g., TOWS [33]) where interactions among decision factors may also be included.

\section{REFERENCES}

[1] L. C. Harris and E. Ogbonna, "Initiating Strategic Planning," Journal of Business Research, Vol. 56, 2006, pp. 100-121. doi:10.1016/i.jbusres.2005.02.003

[2] D. Kellogg and W. A. Nie, "A Framework for Strategic Service Management," Journal of Operation Management, Vol. 3, 1995, pp. 323-337. doi:10.1016/0272-6963(95)00036-4

[3] K. E. Papke-Shields, M. K. Malhotra and V. Grover, "Evolution in the Strategic Manufacturing Planning Process of Organizations," Journal of Operation Management, Vol. 24, 2006, pp. 421-439. doi:10.1016/j.jom.2005.11.012

[4] M. Rhee and S. Mehra, "Aligning Operation, Marketing and Competitive Strategies to Enhance Performance," International Journal of Management Science, Vol. 34, 2006, pp. 505-515.

[5] Y. Sarason and F. Tegarden, "The Erosion of the Com- petitive Advantage of Strategic Planning," Journal of Business and Management, Vol. 9, No. 1, 2003, pp. 1-21.

[6] M. Tanabe, C. F. D. Angelo and N. Alexander, "The Effectiveness of Strategic Planning: Competitiveness in the Brazilian supermarket sector," Journal of Retailing and Consumer Services, Vol. 11, 2004, pp. 51-59. doi:10.1016/S0969-6989(02)00064-4

[7] J. Carlos Bou-Llusar, A. B. Escrig-Tena, V. Roca-Puig and I. Beltrán-Martín, "An Empirical Assessment of the EFQM Excellence Model: Evaluation as a TQM Framework Relative to the MBNQA Model," Journal of Operations Management, In Press.

[8] M. Martínez-Costa and A. R. Martínez Lorente, "ISO 9000 \& TQM: Substitutive or Complementary? An Empirical Study in Industrial Companies," International Journal of Quality and Reliability Management, Vol. 21, No. 3, 2004, pp. 260-276. doi:10.1108/02656710410522711

[9] M. Rodney, L. Denis, J. Henderson and S. A. Hazlett, "Grounded Theory Research Approach to Building and Testing TQM Theory in Operations Management," Omega, Vol. 36, No. 5, 2008, pp. 825-837. doi:10.1016/j.omega.2006.04.005

[10] M. S. Saremi, F. Mousavi and A. Sanayei, "TQM Consultant Selection in SMEs with TOPSIS under Fuzzy Environment," Expert Systems with Applications, In Press, (2008).

[11] T. C. Powell, "Strategic Planning as Competitive Advantage," Strategic Management Journal, Vol. 13, No. 7, 1992, pp. 551-558. doi:10.1002/smj.4250130707

[12] M. Terziovski, P. Fitzpatrick and P. O. Neill, "Successful Predictors of Business Process Reengineering (BPR) in Financial Services," International Journal of Production Economics, Vol. 84, No. 1, 2003, pp. 35-50. doi:10.1016/S0925-5273(02)00378-X

[13] S. Ghazinoory, A. Esmail Zadeh and A. Memariani, "Fuzzy SWOT Analysis," Journal of Intelligent \& Fuzzy Systems, Vol. 18, 2007, pp. 99-108. 
[14] L. Kuo-liang and L. Shu-chen, "A Fuzzy Quantified SWOT Procedure for Environmental Evaluation of an International Distribution Center," Information Sciences, Vol. 178, 2008, pp. 531-549.

doi:10.1016/i.ins.2007.09.002

[15] H. Zhangjiajie, "The Application of Fuzzy Control in Strategic Decision-Making of Small and Medium Enterprises," The International Conference on Measuring Technology and Mechatronics Automation, China, 2009.

[16] K. C. Lee, W. J. Lee, O. B. Kwon, J. H. Han and P. I. Yu, "Strategic Planning Simulation Based on Fuzzy Cognitive Map Knowledge And Deferential Game," Simulation, Vol. 71, No. 5, 1998, pp. 316-327. doi: $10.1177 / 003754979807100503$

[17] H.-F. Wang and W.-Y. Chang, "Fuzzy Scenario Analysis in Strategic Planning," International Journal of General Systems, Vol. 30, No. 2, 2001, pp. 193-201. doi:10.1080/03081070108960705

[18] C. Kahraman, N. Ç. Demirel, T. Demirel and N. Y. Ateş, "A SWOT-AHP Application Using Fuzzy Concept: E-Government in Turkey," Fuzzy Multi-Criteria Decision Making, Vol. 16, 2008, pp. 85-117. doi:10.1007/978-0-387-76813-7_4

[19] S. Li, B. Davies, J. Edwards, R. Kinman and Y. Duan, "Integrating Group Delphi, Fuzzy Logic and Expert Systems for Marketing Strategy Development: The Hybridisation and Its Effectiveness," Marketing Intelligence \& Planning, Vol. 20, No. 5, 2002, pp. 273 -284. doi:10.1108/02634500210441521

[20] S. J. Chen, C. L. Huang and F. P. Huang, "Fuzzy Multiple Attribute Decision Making Method and Application," Springer, Berlin, 1992.

[21] H. H. Chang and W. C. Huang, "Application of a Quantification SWOT Analytical Method," Journal of Mathematical and Computer Modelling, Vol. 43, 2006, pp. 158169. doi:10.1016/j.mcm.2005.08.016

[22] F. R. David, "Strategic Management," Prentice-Hall, New Jersey, 1998.

[23] R. G. Dayson, "Strategic Development and SWOT Analysis at University of Warwick," European Journal of Operation Research, Vol. 152, 2004, pp. 631-640. doi:10.1016/S0377-2217(03)00062-6
[24] L. kue, L. Liang and L. S. Chen, "A Fuzzy Quantified SWOT Procedure for Environment Evaluation of an International Distribution Centre," Information Science, Vol. 178, 2008, pp. 531-549.

[25] I. Yuksel and M. Dagdevirn, "Using the Analytic Network Process (ANP) in a SWOT Analysis-A Case Study for a Textile Firm," Information Sciences, Vol. 177, No. 16, 15 August 2007, pp. 3364-3382. doi:10.1016/j.ins.2007.01.001

[26] K. Altinkemer, A. Chaturvedi and S. Kondareddy, "Business Process Reengineering and Organizational Performance," International Journal of Information Management, Vol. 18, No. 6, 1998, pp. 381-392. doi:10.1016/S0268-4012(98)00030-9

[27] C. V. Altrock and B. Krause, "Multi-Criteria Decision Making in German Automotive Industry Using Fuzzy Logic," Fuzzy Sets and Systems, Vol. 63, No. 3, 1994, pp. 375-380. doi:10.1016/0165-0114(94)90223-2

[28] A. Attaran, "Exploring the Relationship between Information Technology and business process reengineering," Information \& Management, Vol. 41, No. 5, 2004, pp. 585-596. doi:10.1016/S0378-7206(03)00098-3

[29] S. A. Drew and R. Kaye, "Engaging Boards in Corporate Direction Setting: Strategic Scorecards," European Management Journal, Vol. 25, No. 5, 2007, pp. 359-367. doi:10.1016/j.emj.2007.07.006

[30] M. V. Severin and A. Grabski, "Complementary Controls and ERP Implementation Success," International Journal of Accounting Information Systems, Vol. 8, No. 1, 2007, pp. 17-39. doi:10.1016/j.accinf.2006.12.002

[31] J. Yang, C. Wu and C. Tsai, "Selection of an ERP System for a Construction Firm in Taiwan," Automation in Construction, Vol. 16, No. 6, 2007, pp. 787-796. doi:10.1016/j.autcon.2007.02.001

[32] K. Abraham, "Fuzzy Expert Systems," CRC Press, Inc. 1992.

[33] H. Weihrich, "The TOWS Matrix a Tool for Situational Analysis,” Long Range Planning, Vol. 15, No. 2, 1982, pp. 54-66. doi:10.1016/0024-6301(82)90120-0 